\title{
How does participation and browsing affect continuance intention in virtual communities? An integration of curiosity theory and subjective well-being
}

\author{
Yu-Hui Fang ${ }^{\mathrm{a}}$, Chia-Ying Li ${ }^{\mathrm{b} *}$, Ghulam Ali Arain ${ }^{\mathrm{c}}$, and Zeeshan Ahmed Bhatti ${ }^{\mathrm{d}}$ \\ a Department of Accounting, Tamkang University, Tamsui, New Taipei County, Taiwan; \\ ${ }^{b}$ Department of Business Administration, National Taichung University of Science and \\ Technology, Taichung, Taiwan; 'College of Business \& Economics, United Arab Emirates \\ University, Abu Dhabi, United Arab Emirates; ${ }^{\mathrm{d} D e p a r t m e n t ~ o f ~ O p e r a t i o n s ~ a n d ~ S y s t e m s ~}$ \\ Management, University of Portsmouth, Portsmouth, United Kingdom.
}

\begin{abstract}
Based on theories about curiosity and subjective well-being (SWB), this study proposes a research model for how participation and browsing initiate different routes to satisfying members' diverse needs, thus increasing their SWB and their continuance intention in knowledge-based virtual communities (VCs). Two curiosity constructs, informational deprivation epistemic curiosity (DEC) and interest-type epistemic curiosity (I-EC), moderate the wanting route and liking route, respectively. The research model is tested with data from 476 members of one knowledge-based VC using a web survey. Results show that member participation stimulates the wanting route to satisfaction by activating the need for reflective learning and uncertainty reduction, whereas browsing stimulates the liking route to member satisfaction by eliciting enjoyment. Both routes thus increase member SWB and, ultimately, continuance intention. Along the wanting route, D-
\end{abstract}

\footnotetext{
* Contact Chia-Ying Li cyli@ nutc.edu.tw
} 
EC reinforces relationships related to reflective learning but attenuates those related to uncertainty. I-EC alleviates the relationships along the liking route. Comparisons of the relative importance of hypothesized relationships between participants and lurkers indicate that participants feel more satisfied with knowledge sharing, enjoy greater SWB, and maintain higher continuance intention than lurkers. These results can therefore help managers of VCs leverage learning- or fun-oriented mechanisms, depending on member curiosity type.

Keywords: Participation, Browsing, Curiosity, Subjective Well-being, Virtual Communities

\section{Introduction}

Member participation has been acknowledged as the key to success and growth of virtual communities (VCs) (Yang, Li, and Huang 2017; Chiu, Fang, and Wang 2015). Evidence from studies of various industry giants (e.g., Audi, Ducati, Microsoft, and Nokia) supports this conventional logic. Practitioners have further suggested that member participation generates positive benefits for companies and VCs, doing so through such means as knowledge sharing and knowledge collaboration, as well as idea creation for product innovation (Nisar, Prabhakar, and Strakova 2019; Hafeez, Alghatas, Foroudi, Nguyen, and Gupta 2018). As such, participation has been identified as a more active means of interacting with the $\mathrm{VC}$ (a behavior performed by “communicative membership"; Hammond 2000). Alternatively, browsing (reading VC posts by others but rarely posting them) has been recognized as one type of passive and peripheral participation (Chen, Li, Yao, and Zhou 2019; Wenger 2011) that is mainly conducted by the "quiet membership" (Hammond 2000), which comprises the silent

\footnotetext{
$\dagger$ The "quiet membership," peripheral participant, and lurkers are interchangeable in this study.
} 
majority $(90 \%)$ of VC members (Chen et al. 2019; Yang et al. 2017; Nielsen 2011). As Van Mierlo's (2014) study on digital health and social networks indicated, the top 1\% of most active users created $73.6 \%$ of posts on average, whereas $90 \%$ of the remaining population contributed $1.7 \%$ of posts on average. But it is also acknowledged that every VC participant, active or passive, reads more posts than they write (Chen et al. 2019). Notwithstanding the sustainability of VCs requires fresh content and timely interactions (i.e., active participation; Sun, Rau, and Ma 2014), it would be beneficial to study both active and passive participation (browsing) because of the co-occurrence of both behaviors in VCs (Chen et al. 2019; Ebner, Holzinger, and Catarci 2005). And given that membership continuance intention dominates the development of a VC (Fang and Zhang 2019; Fang and Chiu 2010), a natural question to ask is: How can participation and browsing behaviors affect continuance intention in a VC?

To start with, three knowledge gaps in the literature are addressed in this study. First, previous research on VCs has largely focused on the issue of participation (e.g., its antecedents and its effects; Hsu, Wang, and Chih 2018; Peng and Li 2018) and less on that of browsing until recent years (Chen et al. 2019; Yang et al. 2017; Horng 2016). While merely keeping silent (browsing) impairs the vitality of a knowledge-based VC (Sun et al. 2014), most members seldom post in VCs (Yang et al. 2017) viewing browsing as a suitable way to join, and participate in, the community (Chen et al. 2019; Nonnecke, Andrews, and Preece 2006). Chen et al.'s (2019) study verified the value of browsing to a $\mathrm{VC}$ in information diffusion. Although Pöyry, Parvinen, and Malmivaara (2013) confirmed the contributions of both participation and browsing on membership continuance intention, how participation and browsing function through differential routes in a VC remains unknown. Second, prior studies on VC member participation used theories associated with social cognitive, social exchange, social 
capital, and commitment, which have offered unique predictors, such as diverse motivations and social factors (Kang, Han, and Kwon 2018; Giermindl, Strich, and Fiedler 2018; Guo, Liang, Wang, and Peng 2017; Yang et al. 2017; Pai and Tsai 2016; Horng 2016). However, scholars have criticized certain social capital factors (e.g., reciprocity), providing restricted explanations for why people proactively participate in VCs (Pai and Tsai 2016; Tsai and Pai 2013). It is unclear whether these theories and variables would be essential in explaining member browsing in VCs. Third, recent studies on VC found no significant difference in valuation between lurkers and posters in spreading word-of-mouth (Mousavi, Roper, and Keeling 2017), although lurkers and posters incorporate different factors when determining future behaviors and intentions (Chen et al. 2019; Lai and Chen 2014). This observation suggests the need to identify their distinct mindsets towards continuance intention, a line of research that has been neglected. Taken together, it would be enlightening to go beyond these theoretical perspectives to understand both participation and browsing in VCs.

To achieve this goal, this study suggests integrating the notion of subjective well-being and theory of curiosity to break open the "black box" that is the relationship between participation and browsing, and continuance intention. The rationale is fourfold. First, subjective well-being (SWB) refers to "a person's cognitive and affective evaluations of his or her life" (Diener, Lucas, and Oishi 2002, p. 63). While scholars have demonstrated its positive effect on continuance usage intention in computer-media environments (Chiu et al. 2013), Nimrod (2013) called for more research into the different associations between Internet use and SWB in order to evaluate particular online activities and explore diverse audiences. Second, many people join VCs for the purpose of seeking information/knowledge that resolves problems (Singh, Chandwani, and Kumar 2018; Guan, Wang, Jin, and Song 2018), which is related to curiosity theory and the 
psychology of epistemic curiosity (EC) — the desire to gain new knowledge by asking specific, self-reflecting questions or testing hypotheses to arrive at solutions (Fang, Tang, Li, and Wu 2018; Schneider, Von Krogh, and JäGer 2013; Berlyne 1954). According to curiosity theory, Litman's (2010) wanting-liking model of information-seeking links informational deprivationtype EC (D-EC) and interest-type EC (I-EC) to an individual's appetite for (wanting) and pleasure in (liking) acquiring new information (Litman 2008). Accordingly, and to therefore explain continuance intention in VCs, the research framework put forth in this study includes both the wanting route and liking route in evaluating how member participation (active and passive) increases member satisfaction and subsequent SWB. Third, since moderators can systematically alter the strength of the relationship between a predictor and its outcome (Baron \& Kenny, 1986), this study empirically investigates how the reinforcing or attenuating effects of D-EC and I-EC work along the wanting and liking routes, respectively. Fourth, researchers have consistently called for exploring the disparate considerations of active participants and lurkers regarding participation in VCs (e.g., Chen et al. 2019; Chiu et al. 2015). Thus, an interesting research question to be examined in this study is whether active participants and lurkers have different thoughts concerning relationships associated with the wanting route and liking route.

Overall, this study makes four distinct contributions to extant literature. First, while most VC research merely focuses on participation and its antecedents, this study explores how participation and browsing influence membership continuance intention in a VC. Its empirical results support the need to incorporate both behaviors in studying continuance intention. Second, it applies different theoretical perspectives (curiosity theory and SWB) to clarify the issue. It specifically moves in the direction of investigating how participation and browsing initiate different routes to satisfy diverse member needs, thus increasing their SWB and, finally, continuance intention. The 
research conducted here is grounded in the belief that the concepts of SWB and curiosity theory represent an attractive and promising way to remove the knowledge gap, or "black box," between participation and browsing, and continuance intention. Third, the empirical results of this study further suggest that a deeper understanding of both routes to satisfaction is possible when D-EC and I-EC are taken into account, both of which are rarely studied. Fourth, it compares the relative importance of the hypothesized relationships in terms of participant and lurker groups, producing a more sophisticated understanding of the proposed model.

\section{Theoretical background and hypothesis development}

\subsection{Participation and browsing in VCs}

Browsing/lurking is the reserved behavior of reading one or more ongoing conversation strings in a VC but only occasionally contributing content, usually in the form of posting messages or comments (Wairimu and Andoh-Baidoo 2018; Koh, Kim, Butler, and Bock 2007; Rafaeli, Ravid, and Soroka 2004). Being a form of passive and peripheral participation (Chen et al. 2019; Wenger 2011; Koh et al. 2007), it thus contrasts with active participation, which is the process of taking part in or contributing to various activities in a $\mathrm{VC}$ (e.g., posting messages, asking questions, providing information and contributing expertise) (Guan et al. 2018; Ahmad, Philpott, and Duan 2012). Although browsing is very convenient in VCs (Preece, Nonnecke, and Andrews 2004), and peripheral members make up the vast majority of "participants" to date (Chen et al. 2019; Wairimu and Andoh-Baidoo 2018), browsing behavior has received relatively scarce attention, compared to that of participation, due to limited information about such activities (Yang et al. 2017; Rafaeli et al. 2004). Some previous studies consider peripheral members as free-riders and assume a negative posture toward them (Wairimu and Andoh-Baidoo 2018; Sun et al. 2014). They posit that if all 
members were to free-ride on the efforts of others, community-driven knowledge resources would never be generated in the first place (Wairimu and Andoh-Baidoo 2018; Wasko and Faraj 2005). Other studies consider browsing/lurking as a normal and valuable form of online behavior (Chen et al. 2019; Yang et al. 2017; Edelmann 2013). They state that browsing behavior can be perceived as a kind of cognitive apprenticeship (similar to legitimate peripheral participation) (Lave and Wenger 1999). In this way, peripheral members can benefit from knowledge exchanges as well (Sun et al. 2014).

As Chen et al. (2019) concluded, both participation and browsing co-exist in VCs. Active participation is the indispensable condition for successful VCs (Wairimu and Andoh-Baidoo 2018; Koh and Kim 2003), with a VC deemed popular if it has a great number of peripheral members, as they produce website traffic and increase "hits" (Kang, Tang, and Fiore 2014). It is rational then to examine both behaviors simultaneously in VCs, where members are not explicitly instructed to exclude the other type of behavior. As noted, existing research has mostly looked at member participation in VCs from social and commitment perspectives, with emphasis on possible antecedents (Guan et al. 2018; Yang et al. 2017; Horng 2016; Pai and Tsai 2016). Recent studies have looked at predictors of browsing (e.g., fear and guilt; Fang 2017) and de-lurking factors (e.g., social capital factors; Wairimu and Andoh-Baidoo 2018). This study departs from prior work theoretically by exploring how participation and browsing influence continuance intention in VCs. The overall aim also broadens understanding of their relationships in VCs through the lenses of SWB and curiosity theory.

\subsection{Subjective well-being}

Subjective well-being (SWB) represents people's evaluations of their own lives, including both cognitive judgments and affective experiences (Diener et al. 2002). Cognitive judgments 
symbolize conscious evaluation of satisfaction with various aspects of one's life as a whole, including work, interests and engagement. Affective experiences, on the other hand, symbolize feelings, emotions and moods in reaction to conscious evaluation of one's life. Hence, people have high SWB if both their cognitive and affective systems are favorable with regard to what is happening in their lives (Diener 1998). Previous literature postulates that SWB is related to success in the workplace (more productivity and higher organizational commitment) (Lyubomirsky et al. 2005; Pavot and Diener 2004) and the positive effects of community life (loyalty and eWOM) (Chiu et al. 2013; El Hedhli, Chebat, and Sirgy 2013). Although earlier studies have investigated the link between SWB and Internet use (e.g., Valenzuela, Park, and Kee 2009), they emphasize users' satisfaction with real life, rather than satisfaction with online life. More recently, increasing attention has focused on the concept of SWB in various online environments (Munzel, Galan, and Meyer-Waarden 2018; Chiu et al. 2013; Nimrod 2013), with possible antecedents of SWB (e.g., satisfaction, social capital factors, and perceived benefits gained from participation) on social networking sites. However, except for Chiu et al.'s (2013) study, extant literature has yet to address the consequence of SWB in VCs.

In this study, SWB denotes a member's evaluation of his/her happiness and satisfaction with his/her life in the VC. As Diener and Seligman (2009) claim, "well-being [is] not only valuable because it feels good, but...valuable because it has beneficial consequences" (p. 202). Happiness is not only an ultimate goal for human beings, it is also a means for achieving other goals, and encouraging desirable behaviors and outcomes in various domains of life (Larsen and Eid 2008). Generally, SWB can promote members' loyalty to their community (El Hedhli et al. 2013) and continued use of the associated websites (continuance intention) (Chiu et al. 2013). According to Fang (2014), individuals behave similarly in cyberspace as they do in person. It is expected that 
VC members are self-determining and intrinsically encouraged to continue using a VC when they feel happy about doing so (Deci and Ryan 1985). Even in the context of VCs, happiness and positive feelings derived from members' online lives can guide their choice of subsequent actions. That is, if members feel happier about their online lives in a VC (higher SWB), their desire to continue participation in that VC will be stimulated (Dholakia, Bagozzi, and Klein 2004). Thus,

H1: VC members' subjective well-being is positively associated with continuance intention.

In this study, satisfaction with knowledge sharing refers to a pleasurable or positive emotional state stemming from the appraisal of one's knowledge sharing experience in the VC. As one form of evaluation of domain satisfaction, it differs from SWB in that SWB focuses on overall satisfaction and happiness regarding one's online life. As Schimmack (2008) indicates, evaluation of domain satisfaction can change one's SWB. For example, in the workplace, a spillover effect occurs between job satisfaction and SWB (Wilensky 1960). Such an effect reveals that satisfaction in one life domain (e.g., work/job) will affect satisfaction in other life domains (e.g., non-work life), suggesting a positive link between job satisfaction and SWB. In addition, Diener (1984) has asserted that SWB is increased when some positive state of being is achieved, such as relief or satisfaction associated with a goal and/or need being met. Chiu et al. (2013) has also identified satisfaction as a strong predicator of SWB in online contexts. Along the same line of logic, in a $\mathrm{VC}$, if members are satisfied with their knowledge-sharing experience and can realize their goals and needs, they are more likely to feel happier about their VC lives (higher SWB), which is, in part, attributable to a spillover effect. Thus,

H2: VC members' satisfaction with knowledge sharing is positively associated with their subjective well-being. 


\subsection{Curiosity theory and the wanting-liking routes of information-seeking}

Epistemic curiosity (EC), a unique human drive to know, stimulates inquisitiveness and experimentation, inspires intellectual development and scholarly achievement (Berlyne 1954). In the context of knowledge-based VCs, EC is a relevant research issue because it is closely linked to obtaining new information, eliminating information gaps, and tackling intellectual problems (Fang et al. 2018; Fang 2014; Koo and Choi 2010; Schneider et al. 2013). EC involves two underlying goals. The first focuses on eliminating uncertainty and reducing undesirable states of informational deprivation (D-EC), while the second involves acquiring information to simply stimulate positive feelings of interest (I-EC) (Litman 2008). This notion of curiosity parallels Keller, Schneider, and Henderson's (1994) observation that most motivational systems are comprised of both unpleasant and pleasant experiences. For example, hunger may stem from a nutritional deficit, but also from the pleasing sight or smell of food (Litman and Jimerson 2004). Litman's (2010) wanting-liking model of information-seeking, based on curiosity theory, ties DEC and I-EC to distinct levels of an individual's appetite for and pleasure in gaining novel information. Wanting reflects the intensity of hunger for new knowledge and relief from uncertainty in obtaining it; while liking reflects positive feelings stemming from the acquisition of new information. Cooperative but dissociated processes (Berridge 2001), the wanting and liking routes can operate independently (i.e., they can be activated to different degrees), and together affect satisfaction with knowledge acquisition (Litman, Hutchins, and Russon 2005).

Along the same logic, in the context of VCs, participation and browsing may be undertaken by members dependent on the activation of wanting and liking routes, which fulfill distinctive needs (e.g., enjoyment, self-growth). Such needs fulfillment is a fundamental prerequisite for VC membership continuance (Koh and Kim 2003). As such, the extension of wanting-liking routes 
from curiosity theory can shed light on the research question posted in this study due to several rationales. First, the wanting and liking routes have been implicated in reactions to diverse subjects (e.g., food, water, drugs, and sensory stimulation). Previous researchers have not only confirmed their critical role in motivating behavior and stimulating pleasure but also implied that the two routes can mediate reward learning in general (Litman 2005). Second, wanting-liking routes have been theoretically applied by Schneider et al. (2013) to identify individual differences in knowledge acquisition to clarify lurking behavior in VCs. Conceptually, this supports its applicability. Third, "a full understanding of human behavior is impossible without reference to the self' (Leary 1995, p. 157), as is the case in VCs. Thus, this study adopts Leary's suggestion and applies curiosity theory to members' self-perceptions in its exploration of the research question posed.

On the whole, the investigation takes the wanting-liking routes from curiosity theory a further step and examines how participation and browsing initiate different routes to satisfy diverse member needs requisite to SWB, and each member's continuance intention in VCs. Figure 1 illustrates this idea. The upper part of the model depicts the wanting route (participation $\rightarrow$ reflective learning and uncertainty $\rightarrow$ satisfaction), and the lower part represents the liking route (browsing $\rightarrow$ enjoyment $\rightarrow$ satisfaction). Justification for related hypotheses on the wanting and liking routes is described below. In addition, D-EC and I-EC moderate the wanting route and liking route, respectively. Ultimately, this study is thus shaped by the belief that the alternative view of curiosity may shed new light on the relationship between participation and browsing, and continuance intention in VCs. 


\subsection{The wanting route}

According to literature on curiosity, wanting is theorized to promote approach behavior and attribute incentive value to stimuli related to reward (Litman 2005). The wanting system is associated with a variation in deprivation states, the presence of learned incentives for rewards, and the expected promise of a given stimulus to satisfy one's desire, derived from past experience (Litman 2005). Since VC literature recognizes active participation as prerequisite to not only the success of a VC (Chiu et al. 2013; Preece et al. 2004) but also a member's learning process (Alvino et al. 2011), it is reasonable to consider participation as the approach behavior in this study. Applying the wanting system to the context of VCs, members with a strong desire for advanced knowledge are expected to demonstrate active participation in obtaining rewards pertaining to learning that fulfill their needs. Indeed, wanting is aimed at diminishing the unpleasant state of uncertainty and thus relates to an individual's internalized extrinsic motivation, i.e., extrinsic rewards (e.g., learning, own-use value) (Roberts, Hann, and Slaughter 2006), seeing them as an inherent aspect of the task (Litman 2008). Hence, reflective learning and uncertainty reduction are two rewards that need to be satisfied on the wanting route.

Reflective learning is "the process of internally examining and exploring an issue of concern, triggered by an experience, which creates and clarifies meaning in terms of self, and which results in a changed conceptual perspective" (Boyd and Fales 1983, p.100). Such a process not only improves critical thinking skills, but also contributes to the development of new knowledge (Boyd and Fales 1983). According to Wenger (1998), participation is the process of being active in ongoing collective action, through interacting with other participants, sharing ideas and information, as well as common goals, values, resources, and means for action. Given that VC members, usually in need of new information, actively participate by presenting current problems 
or posting comments (Fuller, Jawecki, and Muhlbacher 2007), reflective learning therefore presents a crucial means of fulfilling such needs for information and competence (Chiu et al. 2015). Alvino et al. (2011) state that active participation is the foundation for the learning process, i.e., without participation there is no learning. Consequently, it is expected that the more members participate enthusiastically in a VC, the more reflective learning they can get out of it and benefit from. Thus,

H3a: Participation is positively associated with reflective learning in a VC.

Uncertainty is the extent to which future conditions cannot be precisely predicted because of imperfect information (Pavlou, Liang, and Xue 2007). In the context of this study, uncertainty refers to the degree to which $\mathrm{VC}$ members are uncertain about whether the knowledge/information posted in the forum conversation or discussion may cause suffering associated with adverse outcomes due to difficulty in accurately predicting results or consequences. Literature on curiosity states that people with a desire for novel information tend to engage in exploratory behavior (i.e., active participation, in this case) so as to mitigate uncertainty (Fang et al. 2018; Litman et al. 2005). In a sense, as Fuller et al. (2007) observe, one of the primary goals for joining a $\mathrm{VC}$ is to obtain particular information that diminishes uncertainty or closes knowledge/information gaps. In a similar vein, active participation is analogous to Antheunis, Valkenburg, and Peter's (2010) “interactive strategy," wherein direct interaction with other targets has the aim of gathering more information in order to make more accurate predictions, consequently reducing uncertainty to a significant degree. Accordingly, this study theorizes that, in the context of VCs, when a member engages in more active participation to narrow the knowledge gap, the more likely uncertainty can be reduced.

H3b: Participation is negatively associated with uncertainty in a VC. 
In general, judgments of satisfaction with the experience are established by evaluating consequences of the behavior and interpreting the process (Oliver 1993). According to the central tenet of the wanting route (Litman 2008), reflective learning and alleviation of uncertainty are two critical rewards needing fulfillment in order to form a satisfying experience. Here, reflective learning is concerned with the extent to which a member can learn and expand his/her understanding by investigating his/her own thinking and then using the new knowledge to problem-solve. With regard to the wanting route, from a member's perspective, fulfilling these needs/goals is often a necessary condition for achieving a satisfying knowledge-sharing experience in a VC (Chiu et al. 2015). This logic parallels the argument of goal attainment theory in that people establish goals, and the degree to which these goals are achieved determines their satisfaction (Chiu et al. 2015). Hence, it is rational to hypothesize that:

H4a: Reflective learning is positively related to satisfaction with knowledge sharing in a VC. H4b: Uncertainty is negatively related to satisfaction with knowledge sharing in a VC.

\subsection{The liking route}

The liking system is associated with internalized intrinsic motivation and is an act performed for the enjoyment or inherent interest in doing it (Litman 2008). Unlike the approach behavior on the wanting route, liking elicits a relaxed type of behavior towards the obtainment of knowledge (Litman 2005; 2008), suggesting such behavior is potentially pleasurable but not a necessity. In the context of VCs, browsing can symbolize such behavior on the liking route, being that it represents passive participation and requires less effort than active participation. Moreover, the liking route deals with the evaluation of stimuli pertaining to immediate or expected hedonic impact and corresponding affective value (Litman et al. 2005). Enjoyment can therefore symbolize 
intrinsic reward on the liking route because it has been identified as a critical intrinsic reward in the knowledge sharing process (Chiu et al. 2015; Hau et al. 2013).

In this study, enjoyment, is defined as the extent to which browsing is perceived to be personally enjoyable and fun. Enjoyment points to the performance of a behavior for no apparent reinforcement other than the process of performing it (Deci and Ryan 1985). According to the main tenet of the liking route (Litman 2005; 2008), browsing content in a VC is rewarding in itself because it induces positive feelings of enjoyment from engagement and entertainment related to the acquisition of new information (Fang et al. 2018). Browsing enables the discovery of novel, fun, relevant, understandable, and interesting information (Chen, Shang, and Li 2014) for members, which is similar to Litman's (2005) "novel sensory stimulus". The extent to which this novelty of information is liked may be manipulated by the extent of its cognitive and perceptual interpretability, a quality denoted as "processing ease" or "fluency" (Reber and Schwarz 2002; Litman 2005). Generally, a fluent stimulus is better liked and thus more likely to create positive feelings of enjoyment because less cognitive effort is needed to attain meaningful representations of the stimulus (Litman 2005). Existing work further views information searching (browsing) as a leisure activity (Chen et al. 2014) that results in positive emotional responses (e.g., enjoyment) (Vogt and Fesenmaier 1998). Hence, it is theorized that:

H5: Browsing is positively associated with enjoyment in a VC.

As noted, enjoyment is the critical intrinsic reward to be achieved in order to produce satisfaction on the liking route. In a knowledge-based VC, regardless of member types (active and passive participants, novices, experts, etc.), browsing allows VC members to gather enough information and surf new topics such that it represents a vital mechanism for them to learn and adapt (Schneider et al. 2013). Consequently, enjoyment derived from a pleasant browsing 
experience contributes to member satisfaction with knowledge sharing. Likewise, the aforementioned justification is analogous to the argument of goal attainment theory, wherein the extent to which one's goal (enjoyment, in this case) is realized governs one's degree of satisfaction (Chiu et al. 2015). This link between enjoyment and satisfaction has been supported by Hsu et al. (2014) and Tsai and Pai (2013) in diverse web-based contexts. Thus,

H6a: Enjoyment is positively related to satisfaction with knowledge sharing in a VC.

\section{In addition, previous studies have widely confirmed the positive effect of enjoyment on}

future intentions, such as continuance intention, knowledge sharing, and knowledge contribution in VCs (Singh et al. 2018; Horng 2016; Lai and Chen 2014; Tsai and Pai 2013;). As Nonnecke et al. (2006) note, browsing is one appropriate means for lurkers to participate in a VC. Moreover, enjoyment generated from browsing may be a driving force of continuing membership in a VC. That is, members are better retained if they experience more enjoyment from browsing a VC's content. Hence, the positive relationship between enjoyment and continuance intention can be hypothesized as:

H6b: Enjoyment is positively associated with continuance intention in a VC.

\subsection{D-EC as a moderator of the wanting route}

According to curiosity theory, the extent to which relationships along the wanting and liking routes are varied depends on D-EC and I-EC (Litman 2010). With regard to knowledge seeking and striving for intellectual achievement, Litman (2008) posited that D-EC is more crucial than I-EC. This is because D-EC is more consistent with internalized extrinsic rewards (Litman 2008) and extrinsic learning goals (Piotrowski, Litman, and Valkenburg 2014) (i.e., reflective learning and uncertainty reduction in this case). Accordingly, D-EC is considered a moderator along the wanting route in the current study. D-EC is also associated with a more "integrated" curiosity in 
that it involves a desire for accurate knowledge and concern with reducing one's ignorance (Litman 2010). In one sense, D-EC is extrinsically concerned with the correctness and relevance of new information (Litman 2010), reflecting an intense and uncomfortable "need to know" (Litman 2008), especially in the context of a knowledge-based VC. Hence, it is postulated that members will exert more effort to actively post responses and messages in the $\mathrm{VC}$, leading to a greater extent of reflective learning, and subsequently achieving a higher level of satisfaction with knowledge sharing, but only if D-EC is high in such members. Specifically, it is expected that, under high (low) D-EC, active participation will be more (less) frequent, and its effect on reflective learning will be larger (smaller). Along the same logic, the effect of reflective learning on satisfaction with knowledge experience will be larger (smaller). Thus,

H7a: Participation will have a larger impact on reflective learning when D-EC is high compared to when D-EC is low.

H7b: Reflective learning will have a larger impact on satisfaction with knowledge sharing when D-EC is high compared to when D-EC is low.

Alternatively, for D-EC, obtaining new information through active participation is rewarding since it eases negative feelings attributed to uncertainty (Litman 2010). People with high D-EC tend to view those conditions characterized by uncertainty as bothersome and thus need to eliminate such unpleasant feelings in order to achieve satisfaction. However, previous studies have revealed that D-EC is positively related to approach behavior and extrinsic learning goals but is negatively related to negative affective conditions (Litman 2005; 2010). Applying this logic to the current study, member participation is likely to focus more on the extrinsic reward of reflective learning and less on the unpleasant feelings due to uncertainty when VC members are high in DEC. Under such circumstances, member attention and sensitivity to uncertainty will be attenuated. 
Accordingly, it is expected that members will tend to shift their focus from uncertainty reduction to reflective learning derived from active participation, decreasing not only the effect of participation on uncertainty but also that of uncertainty on satisfaction. Thus,

H7c: Participation will have a smaller impact on uncertainty when D-EC is high compared to when D-EC is low.

H7d: Uncertainty will have a smaller impact on satisfaction with knowledge sharing when DEC is high compared to when D-EC is low.

\subsection{I-EC as a moderator of the liking route}

In contrast to D-EC, I-EC is concerned with obtaining new knowledge simply for the intrinsic joy of it and is related to emotional experiences (Litman 2008) (i.e., the liking route). Since I-EC elicits a pleasant "take it or leave it" feeling towards new knowledge, the acquisition of new information is seen as potentially pleasurable but not a prerequisite if a considerable amount of effort is needed (Fang 2014; Litman 2010). According to curiosity theory, I-EC focuses on the fun of learning new knowledge, while D-EC primarily emphasizes the need to know (e.g., finding solutions to specific problems) (Litman 2008). As Loewenstein (1994) notes, "information seeking is motivated by the aversiveness of not possessing the information more than it is by the anticipation of pleasure from obtaining it" (p. 92). Ultimately, Loewenstein (1994) concludes that D-EC reactions play a more critical role in achieving feelings of competence (reflective learning) than the emotional experiences related to I-EC reactions. In a knowledge-based VC, one of the primary goals for participants is searching information/knowledge in order to solve problems (Singh et al. 2018; Fang and Chiu 2010). Following this logic, it is expected that, under high I-EC, members are less likely to devote their energy to browsing posts, and thus get less enjoyment from it. Such 
conditions are then expected to ultimately lead to a lower degree of satisfaction with knowledgesharing in a VC. Thus,

H8a: Browsing will have a smaller impact on enjoyment when I-EC is high compared to when I-EC is low.

H8b: Enjoyment will have a smaller impact on satisfaction with knowledge sharing when IEC is high compared to when I-EC is low.

\section{Research methodology}

\subsection{Measures}

All measurement items were based on existing validated measures and adapted for this study, being listed and coupled with their sources in Appendix A. All the items were responded to on a sevenpoint Likert scale, with the anchors strongly disagree (1) and strongly agree (7). Note that although participation and browsing can simultaneously happen in a VC, they can be conceptually distinguished and empirically measured. Theoretically, participation focuses on the process of contributing to diverse activities in a VC (Ahmad et al. 2012), whereas browsing is associated with the reserved behavior of reading ongoing conversation strings in a VC (Koh et al. 2007). The items for measuring participation were related to active contribution behaviors (e.g., sharing information, communicating with other people, uploading video or pictures, creating content), while those for measuring browsing were only related to surfing posts in a VC (see Appendix A).

\subsection{Survey administration}

To start with, five professors knowledgeable about the issue of VCs assessed the drafted questionnaire. According to their feedback, certain wording of existing items was revised to more clearly convey the intended meaning of the construct. Initially, the questionnaire was developed 
in English and then translated into Chinese, employing one-way translation, in which one of the authors simply translated the questionnaire from English into Chinese. Other authors then verified the conceptual, rather than literal, equivalence between the two versions. Finally, a pre-test was conducted involving fifteen senior $\mathrm{VC}$ members with information sharing experience in the target $\mathrm{VC}$ to assess its logical consistencies, ease of understanding, sequence of items, and contextual relevance. Minor modifications were applied according to their suggestions. Then the formal survey was conducted online using Google docs.

To test the research model, we surveyed members of the Professional Technology Temple (PTT, http://www.ptt.cc). Using the Telnet protocol, PTT provides an immediate and free online forum community. PTT was chosen because it is one of the largest Chinese language-based bulletin board system in the world and provides great opportunities for information sharing and interaction among members. To date, PTT hosts over 20,000 discussion boards and has more than 1.5 million registered members. Over 40,000 articles and 1 million comments are posted every day. In order to target PTT members, a web-based survey was employed and advertised on particular discussion boards between October and November of 2015. Participation in these boards was available to members interested in sharing and browsing knowledge about photography, language, IT task problems, mobile device design, etc. Only those registered members who had previously visited these boards were invited to participate in this survey.

The first page of the questionnaire explained the purpose of the study, the study procedures (e.g., the length of the questionnaire and the length of time for participation), the risks and benefits of being in the survey, compensation for completing the survey, and lastly, ensured confidentiality. Respondents who agreed and fully finished the questionnaire were offered an incentive of 100 PTT coins. To insure respondent eligibility, we first used two required questions to screen out 
respondents who did not use PTT in the past month and who never posted to PTT since registration. Eligible respondents were then instructed to recall their most impressive participation experience over the last month while replying the survey questions. The returned questionnaires were initially screened for usability and reliability. Finally, 476 complete and valid questionnaires were used for data analysis. Table 1 presents the demographic information of survey respondents. Note that our demographics are in line with the profile of PTT members of two 2015 PTT survey reports in that the majority of members were male $(62 \%)^{\ddagger}$ and between 18 and 22 years of age. ${ }^{\S}$ Accordingly, our study sample can be considered representative of PTT members.

Insert Table 1 about here

\subsection{Data analysis}

The data analysis utilizes a two-step approach as recommended by Anderson and Gerbing (1988). The first step involves analysis of the measurement model, while the second step tests the structural relationships among latent constructs. The two-step approach aims at establishing the reliability and validity of the measures before assessing the structural relationship of the model. PLS (partial least squares, SmartPLS 2.0.M3) (Ringle, Wende, and Will 2005), which places minimal restrictions on measurement scales, sample size, and residual distribution (Chin and Newsted 1999), was used to evaluate both the measurement model and the structural model.

\subsubsection{Measurement Model}

The adequacy of the measurement model was assessed for reliability, convergent validity, and discriminant validity. Reliability was evaluated using composite reliability values. Appendix A shows that all the values are above 0.7, indicating adequate reliability (Fornell and Larcker 1981).

$¥$ goo.gl/2bDGpW, accessed date May $1^{\text {st }}, 2018$.

${ }^{\S} \mathrm{http} / / / \mathrm{disp} . c \mathrm{cc} / \mathrm{m} / 163-8 \mathrm{Zo5}$, accessed date May $1^{\text {st }}, 2018$. 
The convergent validity of the scales was evaluated by two criteria (Fornell and Larcker 1981): (1) all indicator loadings should be significant and exceed 0.7, and (2) average variance extracted (AVE) by each construct should exceed the variance due to measurement error for that construct (i.e., AVE should exceed 0.50). As shown in Appendix A, all items exhibited a loading higher than 0.7 on their respective construct, and all the AVEs ranged from 0.67 to 0.81 , thus satisfying both of the conditions for convergent validity.

Discriminant validity is considered good if three criteria are met. First, the loading of each item on its assigned construct should be larger than its loading on any other construct (Chin 1998). Second, the correlations among all constructs should all be well below the 0.85 threshold, suggesting that all constructs are distinct from each other. Third, the square root of the AVE of a construct should be greater than the correlation between the construct and the other constructs in the model (Fornell and Larcker 1981). As shown in Table 2, all of these criteria are clearly met. Insert Table 2 About Here

In addition, two more tests were applied to evaluate the degree of multicollinearityvariance inflation factors (VIF) and condition numbers. A regression analysis was conducted using continuance intention as the dependent variable and the other nine variables as independent variables. The VIF ranged from 1.11 to 2.61, which are well below the recommended threshold of 3.3 (Diamantopoulos and Siguaw, 2006). The condition number equals the square root of the largest eigenvalue divided by the smallest eigenvalue. Belsley, Kuh, and Welsch (2005) advised that condition numbers less than 10 suggest a weak multicollinearity problem. The condition number for this study is $4.24(\sqrt{ }(4.14 / 0.23))$, which is below 10. Consequently, no significant multicollinearity problem exists in the data. 
To prevent the presence of common method bias in the survey design, several reverse-scored items were first applied to the major constructs in order to avoid acquiescence problems (Lindell and Whitney 2001). Second, after the data were collected, the correlation matrix (Table 2) did not show any highly correlated constructs, while evidence of common method bias usually resulted in extremely high correlations $(r>$.90) (Bagozzi and Phillips 1991). Third, Harman's one-factor test was performed to assess the extent of this bias. The result of the principal components factor analysis demonstrated that the first (largest) factor did not account for a majority of the covariance among all the constructs (13\%), and no single factor emerged from the factor analysis (Podsakoff and Oragn 1986). Overall, all of these results indicate that common method bias is not a major issue in the data.

\subsubsection{Structural Model}

In PLS analysis, examining the structural paths and R-square scores of endogenous variables assesses the explanatory power of a structural model. Figure 2 shows the results of structural path analysis. The path exhibiting a P-value less than 0.05 is considered significant. The significance of all paths was assessed with 500 bootstrap runs. Overall, all of the relevant hypotheses (H1 to H6) were supported, and the structural model explained 33\% of the variance of continuance intention (Figure 2).

Insert Figure 2 About Here

Mediating effects of reflective learning, uncertainty and enjoyment were evaluated following Baron and Kenny's (1986) procedures, which assert that: (1) participation and browsing have significant effects on satisfaction ( $b=0.68$ and 0.18 , respectively); (2) participation has a significant effect on reflective learning $(b=0.20)$ and uncertainty $(b=-0.26)$, while browsing has a significant effect on enjoyment $(b=0.48)$; and $(3)$ reflective learning, uncertainty and enjoyment 
have significant effects on satisfaction $(b=0.25,-0.20$, and 0.22 , respectively). Effects of both participation and browsing on satisfaction are reduced $(b=0.62$ and 0.05$)$ and the browsingsatisfaction link becomes insignificant. Therefore, enjoyment fully mediates the relationship between browsing and satisfaction, while reflective learning and uncertainty act as partial mediators in this model.

Further analyses were performed to examine the moderating hypotheses. D-EC was not a categorical variable, and the groups were divided into high D-EC and low D-EC groups using the median (Baron and Kenny 1986). D-EC was divided by the median of the sum of the four items displayed in Appendix A. Particularly, H7a and H7b were tested by statistically comparing the path coefficients from participating to reflective learning and from reflective learning to satisfaction in the structural model for low D-EC, with corresponding path coefficients in the structural model for high D-EC. A similar procedure was used to test H7c and H7d. Table 3 summarizes the results of moderating effect testing. Consistent with the predicted strength of the two paths, from participation to reflective learning and from reflective learning to satisfaction, both links were stronger for high D-EC members ( $\beta=0.24$ and 0.29 , respectively) than those for low D-EC members $(\beta=0.18$ and 0.16 , respectively), which supports $\mathrm{H} 7 \mathrm{a}$ and $\mathrm{H} 7 \mathrm{~b}(\mathrm{t}=16.35$ and $38.15, p<.001)$. Contrary results were found for the alternative path along the wanting route. Both links, from participation to uncertainty and from uncertainty to satisfaction were weaker for high D-EC members ( $\beta=-0.21$ and -0.20 , respectively) than those for low D-EC members $(\beta=-0.30$ and -0.21 , respectively). Such differences were statistically significant $(\mathrm{t}=32.70$ and $3.63, p<.001)$ in support of $\mathrm{H} 7 \mathrm{c}$ and $\mathrm{H} 7 \mathrm{~d}$. For I-EC, its moderating effects along the liking route were consistent with the authors' expectations (Table 3). For VC members displaying a higher I-EC, browsing is shown to have less influence on enjoyment $(\beta=0.46)$ than those displaying a lower I-EC $(\beta=$ 
0.51), which supports H8a $(\mathrm{t}=20.56, p<.001)$. Similarly, enjoyment is shown to have less influence on satisfaction $(\beta=0.16)$ than those displaying a lower I-EC $(\beta=0.28)$, thus supporting $\mathrm{H} 8 \mathrm{~b}(\mathrm{t}=32.35, p<.001)$.

\section{Insert Table 3 About Here}

In addition, post-hoc analyses were conducted by running further models to examine whether active participants and passive participants have different perceptions about relationships associated with the wanting route and liking route. With regard to classification of the active and passive participant groups, Nonnecke and Preece's (2000) lurker definition was adopted, which assumes that a member who posts articles infrequently — contributing nothing to the $\mathrm{VC}$ during a three-month period — is a lurker (passive participant). In the survey, respondents were required to indicate how many times they had posted messages or feedback to the community in the past three months. Consequently, the data included 201 active participants and 275 passive participants. Figure 3 illustrates the results of the two structural models for both participant groups. In brief, results show that the two groups exhibited differences in the strength of model relationships. For active participants, both participation and browsing can have more influence on reflective learning and enjoyment ( $\beta=0.32$ and 0.59 , respectively), versus that for passive participants ( $\beta=0.13$ and 0.40). Under such conditions, reflective learning and enjoyment contribute more to their satisfaction ( $\beta=0.41$ and 0.27 , respectively) than that of passive participants ( $\beta=0.16$ and 0.24$)$. However, those path coefficients between participation and uncertainty, and uncertainty and satisfaction $(\beta=-0.20$ and -0.10 , respectively), are lower than those associated with passive participation ( $\beta=-0.25$ and -0.20 ). This implies that, with regard to knowledge-sharing satisfaction, active participants rely less on uncertainty than passive participants. Alternatively, the explanatory power of structural models can be assessed by looking at the $\mathrm{R}^{2}$ value in the final dependent 
variable (Wasko and Faraj 2005). Overall, the structural model for active participants explained higher percentages (42\% and 36\%) of variance in SWB and continuance intention than that for passive participants (26\% and $32 \%$, respectively).

Insert Figure 3 About Here

\section{Discussion and implications}

The purpose of this study is to gain a better understanding of how participation and browsing influence continuance intention in knowledge-based VCs. Empirical findings support the view that participation and browsing significantly influence SWB and subsequent continuance intention along the wanting route and liking route. Briefly, the wanting route begins with member participation so as to gain the reward of reflective learning and reduce uncertainty, which in turn contributes to member satisfaction with knowledge-sharing. Alternatively, the liking route begins with member browsing in order to achieve the intrinsic reward of enjoyment, and then satisfaction. Satisfaction with knowledge-sharing thus acts as a critical determinant of SWB, which ultimately contributes to membership continuance intention in a VC. Furthermore, for D-EC, its reinforcing effects on both paths, from participation to reflective learning and reflective learning to satisfaction, are verified in this investigation. Yet, D-EC attenuates relationships between participation, uncertainty, and satisfaction. Finally, it was found that I-EC negatively moderates relationships between browsing, enjoyment and satisfaction in the context of knowledge-based VCs. In the sections that follow, each of these results are discussed in turn, along with their theoretical implications and some directions for further research.

\subsection{Theoretical implications}

Based on curiosity theory and the notion of SWB, this study is distinguished from existing work in that it investigates how participation and browsing along wanting and liking routes satisfy 
diverse member needs, thus increasing their SWB and, finally, their continuance intention. Empirical support was found for the proposition that both the wanting route and liking route can contribute to predicting members' SWB and continuance intention. The results are of great importance because the majority of research in this area has focused on the determinants of participation and browsing but ignore how members benefit from their particular behavior. In a sense, this study also addresses recent calls for including desires (i.e., the wanting route), which are fundamental psychological states and necessary for converting reasons for action into intentions to act in different decision making models (Tsai and Bagozzi 2014). Taken together, this study is an important step in this direction because it is one of the first that empirically investigates several links along both the wanting and liking routes in VCs by integrating various tenets of curiosity theory and SWB.

Consistent with prior research in management (Chiu et al. 2013; Schimmack 2008), satisfaction is a strong predictor of SWB in the context of VCs, with a path coefficient of 0.56. Particularly, evidence found in the current study demonstrates that reflective learning, uncertainty reduction, and enjoyment contribute to members' satisfaction with their knowledge sharing experience. The findings are as expected, demonstrating that enhanced satisfaction, ensuing from key aspects of rewards along both the wanting and the liking routes, may in turn prompt members to achieve SWB in a VC. Future research is needed to explore other possible rewards along the wanting and liking routes so as to better understand member satisfaction and SWB in VCs. Among the three rewards, reflective learning $(\beta=0.25)$ is relatively more important than uncertainty and enjoyment in shaping member satisfaction with knowledge sharing $(\beta=-0.20$ and 0.22 , respectively). Results suggest that members in a knowledge-based VC care more about the reward of reflective learning than other rewards in determining their satisfaction. Indeed, reflective 
learning (e.g., learning something from discussing questions and applying the learned knowledge to enhance efficiency in problem-solving) is one of the essential rewards that members desire to obtain in a VC. Nevertheless, to date, the role of reflective learning has not received much attention in VC literature. What this study does then is provide a good starting point for further studies on the role of reflective learning in VCs.

With regard to the wanting route, findings in the current study further indicate that, for reflective learning to be attained, $\mathrm{VC}$ members must actively participate (e.g., frequently contribute information and/or comments) $(\beta=0.20)$. This is in line with the notion of "learning by doing." Furthermore, this trend is more pronounced for the active-participant group ( $\beta=0.32)$ than the passive-participant group $(\beta=0.13)$ (Figure 3). In contrast, it was confirmed that uncertainty can be lessened when participation increases $(\beta=-0.26)$. But the strength of the path from participation to uncertainty gets weaker for active participants $(\beta=-0.20)$ than for passive participants $(\beta=-0.25)$ (Figure 3). It appears that active participants are more likely to achieve the reward of reflective learning derived from active participation and are less concerned about the reduction of uncertainty than passive participants. Also, for active participants, their enhanced satisfaction is, relatively speaking, derived more from reflective learning $(\beta=0.41)$ and less from uncertainty $(\beta=-0.10)$, subsequently producing higher SWB and higher continuance intention compared to that of passive participants. Overall, this implies that active participants feel happier continuing their membership in a VC because they feel satisfied with their learning experiences.

Moreover, this study advances current understanding of the role of enjoyment in VC literature. The contribution of enjoyment examined here departs from prior research (e.g., Wasko and Faraj 2005) in that it is found to be primarily generated from browsing behavior rather than helping other members. Such browsing enjoyment has been discussed in the marketing field but 
not in the context of VCs. According to marketing literature, the viewing of merchandise (window shopping) may satisfy consumers' desire for exploration and novelty seeking (Steenkamp and Baumgartner 1992), thus creating the feeling of enjoyment. In a similar vein, browsing in a VC corresponds to window shopping in a store and is viewed as a leisure activity (Chen et al. 2014). Researchers have further suggested that entertainment factors should be included in behavioral models as a means to realize the evaluative judgments of members on community usage (Tsai and Pai 2013). As such, this study contributes to the VC literature by addressing this concern. Furthermore, the current study tested the link between browsing and uncertainty and found that its path coefficient $(\beta=-0.03)$ is insignificant. The result implies that browsing can play a role along the liking route but is not necessary along the wanting route because, while merely browsing may evoke positive feelings, it cannot solve uncertainty. Regarding the liking route, the strength of both paths (from browsing to enjoyment, and from enjoyment to satisfaction) are stronger for active participants ( $\beta=0.59$ and 0.27 , respectively) than those for passive participants $(\beta=0.40$ and 0.24 , respectively) (Figure 3). This suggests that, even along the liking route, active participants feel more pleased with their browsing experiences and the resulting enjoyment than passive participants, which then intensifies the extent of their satisfaction.

The findings also demonstrate the moderating effects of D-EC and I-EC on the wanting and liking routes, respectively. The resulting evidence suggests that a deeper understanding of the relationships among constructs along both routes is possible when interactions are taken into consideration. Specifically, expected results along the wanting route support this study's hypotheses that D-EC can intensify the participation-reflective learning link and reflective learning-satisfaction link ( $\mathrm{H} 7 \mathrm{a}$ and $\mathrm{H} 7 \mathrm{~b})$, but can attenuate the participation-uncertainty and uncertainty-satisfaction links (H7c and H7d) (Table 3). These findings subsequently coincide with 
Litman's $(2005 ; 2010)$ argument that D-EC is positively linked to approach behavior and extrinsic learning goals, but negatively linked to negative affective conditions (Litman 2005; 2010). This implies that the active participation of high D-EC members is more closely associated with reflective learning, and less so to uncertainty reduction when they evaluate satisfaction. Alternatively, for the liking route, results confirm the investigation's hypotheses that assert I-EC can attenuate the relationships between browsing, enjoyment and satisfaction (H8a and H8b) (Table 3). As aforementioned, I-EC manifests a relaxed and pleasant "take it or leave it" tendency towards the acquisition of new information. Findings further suggest that browsing in this context can be seen as a means for information-seeking and may, more or less, involve a certain amount of effort to do. Therefore, browsing cannot completely be linked to the "take it or leave it" type of behavior associated with high I-EC members. In this way, high I-EC members are less likely to browse and experience less enjoyment from it, which in turn leads to lower satisfaction with knowledge sharing than that experienced by low I-EC members. Altogether, results confirm previous work (Litman 2008) in that D-EC is more vital than I-EC with regard to informationseeking. Ultimately, the findings broaden understanding of what types of members are more attracted to active participation and its concomitant rewards in knowledge-based VCs.

\subsection{Managerial implications}

It is believed that this study can contribute to practitioner knowledge with some important implications. First, findings in this case suggest that reflective learning is a more attractive reward in activating member satisfaction than uncertainty reduction and enjoyment. However, from the perspective of a VC manager, it would be especially unfortunate to interpret these results as implying that uncertainty reduction and enjoyment will garner less attention by VC members. The appropriate interpretation is that, given the situational context of this investigation's sampling, 
further increases in uncertainty reduction and enjoyment may be less potent than similar increases in reflective learning. But again, the importance of uncertainty reduction and enjoyment cannot be overlooked. Designers of VCs can then build a more reliable and enjoyable environment in a few different ways. First, they can include innovative multimedia tools and techniques to make the participation process and interaction among members more interesting and entertaining. Second, a VC manager can encourage members to provide interesting and reliable content. VC designers can also create mechanisms to detect untruthful information in order to promote and maintain forum reliability and integrity. Finally, VC managers can manipulate reflective strategies in order to encourage discussion and communication among members, which will intensify their enjoyment of knowledge sharing in the VC.

Findings secondly reveal that active participants, in general, are more satisfied with knowledge sharing, enjoy greater SWB, and maintain higher continuance intention than members in the passive group. From a member's perspective, this study encourages him/her to be an active participant in a knowledge-based $\mathrm{VC}$ because both participation and browsing can lead to more rewards, satisfaction, and SWB than that experienced by a passive participant. For a VC manager, he/she may be advised to educate members about what rewards they can achieve through active participation and browsing. Such managerial efforts may eventually facilitate enthusiastic continuance intention, as well as participation in and use of a VC. This is good news for the manager because happier members will automatically engage in forum discussions and provide feedback once they truly understand that the practice of learning by doing in the context of a VC indeed works and benefits them.

Third, findings reveal that both active participation and browsing contribute to member satisfaction and SWB through different rewards. It has been acknowledged that members with the 
ability to provide useful knowledge may assess how others behave, which influences their decisions for further actions (Fang and Chiu 2010). Given that browsing cannot be easily traced in the context of a $\mathrm{VC}$, designers are encouraged to create and implement a mechanism that can expose browsing and participation behaviors, such as the 4-point mechanism employed in one IToriented VC in Taiwan (Fang and Chiu 2010). Members can earn a variety of points based on their frequency of participation in the $\mathrm{VC}$, the number of responses posted, the degree of their contribution quality, and the number of useful files uploaded. Members in the VC can also observe others' active participation and contribution levels using these points. This mechanism, in the context of a VC, exemplifies a practical way to apply the Dakota proverb: "We will be known forever by the tracks we leave."

Finally, based on study findings associated with the moderating effects of D-EC and I-EC, it is suggested that designers and managers leverage appropriate mechanisms to identify member curiosity types and then promote to them suitable strategies and tools depending on their type. For example, for high D-EC members, recommendations can be made for the use of tools and approaches, such as reflective metaphors, reflective journals, and reflective dialogue, to clarify their thinking, achieve deep learning, and stretch their abilities. For high I-EC members, recommendations include: (1) development of systems that can rate the difficulty or easiness of content posted in a forum's display content using simple and fun formats, and (2) development of fun interactions among members corresponding to their fun-oriented tendencies. Such systems may further help high I-EC members expend less effort in browsing while generating more fun and entertaining experiences in a VC. 


\subsection{Limitations and future research directions}

We note that our findings have several limitations. First, accounting to curiosity theory, only DEC and I-EC were selected as moderators in the model considered here. Future research is encouraged to employ other relevant theories and investigate other possible moderators (e.g., personality and situational factors) that transform key effects into more thoughtful and systematic relationships. For instance, the "Big Five" personality traits have been found to be useful in understanding human behavior. Thus, an interesting line of future research would be to extend the research model to exploring the usefulness of the "Big Five" personality traits on continuation intention in VCs and examining their possible moderating effects. Second, since the data are crosssectional, all statistically-supported relationships can be viewed as only tentative and associational. Future research could longitudinally test the proposed model to verify causal interrelationships among these constructs. Third, the results may have been impacted by selection bias, since the sample considered was comprised of only current members. Individuals who left the VC might have different perceptions about the influence of participation and browsing. Therefore, the results should be interpreted as only explaining SWB and continuance intentions of current members in a VC. Future research could also explore possible factors that influenced the decision by such individuals to leave their VCs. Fourth, this study focuses on members of knowledge-based VCs. Behaviors may differ in other types of VCs (e.g., affect-oriented VCs and hobby-oriented VCs). Ultimately, further exploration that extends use of this study model to other settings would be valuable. Fifth, this study tested the hypotheses using data exclusively collected from PTT members in terms of their subjective views because individuals' subjective perceptions can govern their future intentions and actions (Fang 2014). Future research could complement the survey with 
other data (e.g., using semantic analysis to identify the emotion of participants and evaluate the quality of their posting content) after obtaining participants' permission.

\section{References}

Ahmad, A., E. Philpott, and Y. Duan. 2012. "Developing A Conceptual Framework for Factors Affecting Active Participation in Business to Business Online Business Communities." UK Academy for Information Systems Conference Proceedings 2012. Paper 39. http://aisel.aisnet.org/ukais2012/39

Alvino, F., R. Agrifoglio, C. Metallo, and L. Lepore. 2011. "Learning and Knowledge Sharing in Virtual Communities of Practice: A Case Study. In Information Technology and Innovation Trends in Organizations, edited by A. D’Atri, M. Ferrara, J. F. George, and P. Spagnoletti, 425-432. Physica-Verlag HD.

Anderson, J. C., and D. W. Gerbing. 1988. "Structural Equation Modeling in Practice: A Review and Recommended Two-Step Approach.” Psychological Bulletin 103 (3): 411-423.

Antheunis, M. L., P. M. Valkenburg, and J. Peter. 2010. "Getting Acquainted through Social Network Sites: Testing A Model of Online Uncertainty Reduction and Social Attraction." Computers in Human Behavior 26 (1): 100-109.

Bagozzi, R., Y. Yi, and L. Phillips. 1991. "Assessing Construct Validity in Organizational Research.” Administrative Science Quarterly 36 (3): 421-458.

Baron, R. M., and D. A. Kenny. 1986. "The Moderator-mediator Variable Distinction in Social Psychological Research: Conceptual, Strategic, and Statistical Considerations." Journal of Personality and Social Psychology 51: 1173-1182.

Berlyne, D.E. 1954. “A Theory of Human Curiosity.” British Journal of Psychology 45: 180-191.

Belsley, D. A., E. Kuh, and R. E. Welsch. 2005. Regression Diagnostics: Identifying Influential Data and Sources of Collinearity. (Vol. 571). New York: John Wiley \& Sons Inc.

Berridge, K. C. 2001. "Reward Learning: Reinforcement, Incentives and Expectations." In Psychology of Learning and Motivation (Vol. 40), edited by D. L. Medin, 223-278. Orlando, FL: Academic Press.

Bhattacherjee, A. 2001. "Understanding Information Systems Continuance: An ExpectationConfirmation Model." MIS Quarterly 25: 351-370. 
Boyd, E. M., and A. W. Fales. 1983. "Reflective Learning Key to Learning from Experience.” Journal of Humanistic Psychology 23 (2): 99-117.

Casaló, L. V., C. Flavián, and M. Guinalíu. 2010. “Antecedents and Consequences of Consumer Participation in On-line Communities: The Case of the Travel Sector.” International Journal of Electronic Commerce 15 (2): 137-167.

Chen, X., X., Li, D. Yao, and Z. Zhou. 2018. "Seeking the Support of the Silent Majority: Are Lurking Users Valuable to UGC Platforms?" Journal of the Academy of Marketing Science https://doi.org/10.1007/s11747-018-00624-8

Chen, Y. C., R. A. Shang, and M. J. Li. 2014. “The Effects of Perceived Relevance of Travel Blogs' Content on the Behavioral Intention to Visit a Tourist Destination." Computers in Human Behavior 30: 787-799.

Chin, W.W. 1998. "Issues and Opinion on Structural Equation Modeling.” MIS Quarterly 22 (1): $7-16$.

Chin, W. W., and P. R. Newsted. 1999. "Structural Equation Modeling Analysis with Small Samples Using Partial Least Squares.” In Statistical Strategies for Small Sample Research, edited by R. H. Hoyle, 307-341. Thousand Oaks: Sage Publications.

Chiu, C. M., H. L. Cheng, H. Y. Huang, and C. F. Chen. 2013. 'Exploring Individuals' Subjective Well-being and Loyalty towards Social Network Sites from the Perspective of Network Externalities: The Facebook Case.” International Journal of Information Management 33 (3): 539-552.

Chiu, C. M., Y. H. Fang, and E. T. Wang. 2015. "Building Community Citizenship Behaviors: The Relative Role of Attachment and Satisfaction." Journal of the Association for Information Systems 16 (11): 947-979.

Dholakia, U. M., R. P. Bagozzi, and L. R. Klein. 2004. “A Social Influence Model of Consumer Participation in Network and Small Group-based Virtual Communities." International Journal of Research in Marketing 21 (3): 241-263.

Deci, E. L., and R. M. Ryan. 1985. Intrinsic Motivation and Self-determination in Human Behavior. New York: Plenum.

Diamantopoulos, A., and J. A. Siguaw. 2006. "Formative versus Reflective Indicators in Organizational Measure Development: A Comparison and Empirical Illustration.” British Journal of Management 17 (4): 263-282. 
Diener, E. 1984. “Subjective Well-being.” Psychological Bulletin 95: 542-575.

Diener, E. 1998. Subjective Well-being and Personality. In Advanced Personality, edited by E. Diener, D. F. Barone, and M. Hersen, 311-334. US: Springer.

Diener, E., R. A. Emmons, R. J. Larsen, and S. Griffin. 1985. "The Satisfaction with Life Scale.” Journal of Personality Assessment 49: 71-75.

Diener, E., R. E. Lucas, and S. Oishi. 2002. "Subjective Well-being: The Science of Happiness and Life Satisfaction.” In Handbook of Positive Psychology, edited by C. R. Snyder and S. J. Lopez, 63-73. New York: Oxford University Press.

Diener, E., and M. E. Seligman. 2009. Beyond Money: Toward an Economy of Well-being. In The Science of Well-Being, edited by E. Diener, 201-265. Netherlands: Springer.

Ebner, M., A. Holzinger, and T. Catarci. 2005. "Lurking: An Underestimated Human Computer Phenomenon." Multimedia 12 (4): 70-75.

Edelmann, N. 2013. "Reviewing the Definitions of "Lurkers" and Some Implications for Online Research.” Cyberpsychology, Behavior, and Social Networking 16 (9): 645-649.

El Hedhli, K., J. C. Chebat, and M. J. Sirgy. 2013. "Shopping Well-being at the Mall: Construct, Antecedents, and Consequences." Journal of Business Research 66 (7): 856-863.

Fang, C., and J. Zhang. 2019. "Users' Continued Participation Behavior in Social Q\&A Communities: A Motivation Perspective.” Computers in Human Behavior 92: 87-109.

Fang, Y. H. 2014. "Beyond the Credibility of Electronic Word of Mouth: Exploring EWOM Adoption on Social Networking Sites from Affective and Curiosity Perspectives.” International Journal of Electronic Commerce 18 (3): 67-102.

Fang, Y. H. 2017. “Coping with Fear and Guilt Using Mobile Social Networking Applications: Knowledge Hiding, Loafing, and Sharing." Telematics and Informatics 34 (5): 779-797.

Fang, Y. H., and C. M. Chiu. 2010. "In Justice We Trust: Exploring Knowledge-sharing Continuance Intentions in Virtual Communities of Practice." Computers in Human Behavior 26 (2): 235-246.

Fang, Y. H., K., Tang, C. Y., Li, and C. C. Wu. 2018. “On Electronic Word-of-mouth Diffusion in Social Networks: Curiosity and Influence." International Journal of Advertising 37 (3): 360-384.

Featherman, M., and M. Fuller, 2003. “Applying TAM to E-services Adoption: The Moderating Role of Perceived Risk." In Proceedings of the 36th Annual Hawaii International Conference 
on System Sciences, Big Island: IEEE.

Fornell, C., and D. F. Larcker. 1981. "Structural Equation Models with Unobservable Variables and Measurement Errors." Journal of Marketing Research 18 (1): 39-50.

Fuller, J., G. Jawecki, and H. Muhlbacher. 2007. "Innovation Creation by Online Basketball Communities.” Journal of Business Research 60 (1): 60-71.

Giermindl, L., F. Strich, and M. Fiedler. 2018. "How Do They Differ? Analyzing the Motivations of Posters and Lurkers for Participation in Enterprise Social Networks." Journal of Information Technology Theory and Application, 19 (2): 89-120.

Guan, T., L. Wang, J. Jin, and X. Song. 2018. "Knowledge Contribution Behavior in Online Q\&A Communities: An Empirical Investigation.” Computers in Human Behavior 81: 137-147.

Guo, W., R. Y. Liang, L. Wang, and W. Peng. 2017. "Exploring Sustained Participation in Firmhosted Communities in China: The Effects of Social Capital and Active Degree." Behaviour \& Information Technology 36 (3): 223-242.

Hafeez, K., F. M. Alghatas, P. Foroudi, B. Nguyen, and S. Gupta. 2018. "Knowledge Sharing by Entrepreneurs in a Virtual Community of Practice." Information Technology \& People. https://doi.org/10.1108/ITP-09-2016-0202

Hammond, M. 2000. "Communication within Online Forums: The Opportunities, the Constraints and the Value of a Communicative Approach." Computers \& Education 35 (4): 251-262.

Hau, Y. S., B. Kim, H. Lee, and Y. G. Kim. 2013. "The Effects of Individual Motivations and Social Capital on Employees' Tacit and Explicit Knowledge Sharing Intentions.” International Journal of Information Management 33 (2): 356-366.

Horng, S. M. 2016. "A Study of Active and Passive User Participation in Virtual Communities.” Journal of Electronic Commerce Research, 17(4): 289-311.

Hsu, J. S., T. C. Lin, and J. Tsai. 2014. "Does Confirmation Always Matter? Extending Confirmation-based Theories.” Behaviour \& Information Technology 33 (11): 1219-1230.

Hsu, L. C., K. Y. Wang, and W. H. Chih. 2018. "Investigating Virtual Community Participation and Promotion from a Social Influence Perspective." Industrial Management \& Data Systems 118 (6): 1229-1250.

Kang, H. J., J. Han, and G. H. Kwon. 2018. “An Integrated Success Factor Model of Professional Virtual Communities: Incorporation of the Operators, Members, and Life Cycle Perspectives.” 
International Journal of Human-Computer Interaction, https://doi.org/10.1080/ 10447318.2018.1519977

Kang, J., L. Tang, and A. M. Fiore. 2014. "Enhancing Consumer-brand Relationships on Restaurant Facebook Fan Pages: Maximizing Consumer Benefits and Increasing Active Participation." International Journal of Hospitality Management 36: 145-155.

Keller, H., K. Schneider, and B. Henderson, 1994. Preface: The Study of Exploration. In Curiosity and Exploration, edited by H. Keller, K. Schneider and B. Henderson, 199-212. Berlin: Springer.

Kim, Y. J., J. Baker, and J. Song, 2007. "An Exploratory Study of Social Factors Influencing Virtual Community Members' Satisfaction with Avatars." Communications of the Association for Information Systems 20 (1): 567-593.

Koh, J., and Y. G. Kim. 2003. "Sense of Virtual Community: A Conceptual Framework and Empirical Validation.” International Journal of Electronic Commerce 8 (2): 75-94.

Koh, J., Y. G. Kim, B. Butler, and G. W. Bock. 2007. "Encouraging Participation in Virtual Communities." Communications of the ACM 50 (2): 68-73.

Koo, D. M., and Y. Y. Choi. 2010. "Knowledge Search and People with High Epistemic Curiosity." Computers in Human Behavior 26 (1): 12-22.

Lai, H. M., and T. T. Chen. 2014. "Knowledge Sharing in Interest Online Communities: A Comparison of Posters and Lurkers." Computers in Human Behavior 35: 295-306.

Larsen, R. J., and M. Eid, 2008. Ed Diener and the Science of Subjective Well-being. In The Science of Subjective Well-being, 1-13, edited by M. Eid and R. J. Larsen, New York: Guilford Press.

Lave, J., and E. Wenger. 1999. Legitimate Peripheral Participation. In Learners, Learning and Assessment, 83-89, edited by P. Murphy, London: The Open University.

Leary, M. R. 1995. Self-Presentation: Impression Management and Interpersonal Behavior, Boulder, CO: Westview Press.

Lindell, M. K., and D. J. Whitney. 2001. "Accounting for Common Method Variance in CrossSectional Research Designs." Journal of Applied Psychology 86 (1): 114-121.

Litman, J. 2005. "Curiosity and the Pleasures of Learning: Wanting and Liking New Information." Cognition \& Emotion 19 (6): 793-814.

Litman, J. A. 2008. "Interest and Deprivation Factors of Epistemic Curiosity." Personality and 
Individual Differences 44 (7): 1585-1595.

Litman, J. A. 2010. "Relationships between Measures of I- and D-type Curiosity, Ambiguity Tolerance, and Need for Closure: An Initial Test of the Wanting-liking Model of Informationseeking." Personality and Individual Differences 48 (4): 397-402.

Litman, J. A., T. L. Hutchins, and R. K. Russon. 2005. "Epistemic Curiosity, Feeling-of Knowing, and Exploratory Behaviour." Cognition \& Emotion 19 (4): 559-582.

Litman, J. A., and T. L. Jimerson. 2004. "The Measurement of Curiosity as a Feeling of Deprivation." Journal of Personality Assessment 82 (2): 147-157.

Loewenstein, G. 1994. "The Psychology of Curiosity: A Review and reinterpretation." Psychological Bulletin 116 (1): 75-98.

Lyubomirsky, S., L. King, and E. Diener. 2005. "The Benefits of Frequent Positive Affect: Does Happiness Lead to Success?" Psychological Bulletin 131: 803-855.

Mousavi, S., S. Roper, and K. A. Keeling. 2017. "Interpreting Social Identity in Online Brand Communities: Considering Posters and Lurkers." Psychology \& Marketing 34(4): 376-393.

Munzel, A., J. P. Galan, and L. Meyer-Waarden. 2018. "Getting By or Getting Ahead on Social Networking Sites? The Role of Social Capital in Happiness and Well-Being." International Journal of Electronic Commerce 22 (2): 232-257.

Nielsen, J. 2011. Participation Inequality: Encouraging More Users to Contribute. Accessed May. 14, 2018. http://www.useit.com/alertbox/participation_inequality.html.

Nelson Laird, T. F. N., R. Shoup, and G. D. Kuh. 2005. Deep Learning and College Outcomes: Do Fields of Study Differ? Annual Meeting of the Association for Institutional Research. San Diego.

Nimrod, G. 2013. "Challenging the Internet Paradox: Online Depression Communities and Wellbeing." International Journal of Internet Science 8 (1): 30-48.

Nisar, T. M., G. Prabhakar, and L. Strakova. 2019. "Social Media Information Benefits, Knowledge Management and Smart Organizations.” Journal of Business Research 94: 264272.

Nonnecke, B., and J. Preece. 2000. Lurker Demographics: Counting the Silent. In Proceedings of the SIGCHI Conference on Human Factors in Computing Systems, 73-80. ACM.

Nonnecke, B., D. Andrews, and J. Preece. 2006. "Non-public and Public Online Community Participation: Needs, Attitudes and Behavior." Electronic Commerce Research 6 (1): 7-20. 
Novak, T. P., D. L. Hoffman, and Y. F. Yung. 2000. "Measuring the Customer Experience in Online Environments: A Structural Modeling Approach.” Marketing Science 19 (1): 22-42.

Oliver, R. L. 1993. "Cognitive, Affective, and Attribute Bases of the Satisfaction Response." Journal of Consumer Research 20: 418-430.

Pai, P., and H. T. Tsai. 2016. "Reciprocity Norms and Information-sharing Behavior in Online Consumption Communities: An Empirical Investigation of Antecedents and Moderators." Information \& Management, 53(1): 38-52.

Pavlou, P.A., H. Liang, and Y. Xue. 2007. "Understanding and Mitigating Uncertainty in Online Exchange Relationships: A Principal-agent Perspective.” MIS Quarterly 31: 105-136.

Pavot, W., and E. Diener, 2004. Findings on Subjective Well-being: Applications to Public Policy, Clinical Interventions, and Education. In Positive Psychology in Practice, 679-692. P. A. Linley and S. Joseph, Hoboken, NJ: Wiley.

Peng, Y., and Y. J. Li, 2018. "Research on User's Interaction Participation in Virtual Communities Based on the Information Ecology Theory." Journal of Mathematics and Informatics 14: 53 61.

Piotrowski, J. T., J. A. Litman, and P. Valkenburg. 2014. "Measuring Epistemic Curiosity in Young Children." Infant and Child Development 23 (5): 542-553.

Priem, R. L., L. G. Love, and M. A. Shaffer. 2002. "Executives' Perceptions of Uncertainty Sources: A Numerical Taxonomy and Underlying Dimensions." Journal of Management 28: 725-746.

Podsakoff, P. M., and D. W. Organ. 1986. "Self-reports in Organizational Research: Problems and Prospects." Journal of Management 12, 531-544.

Pöyry, E., P. Parvinen, and T. Malmivaara. 2013. "Can We Get from Liking to Buying? Behavioral Differences in Hedonic and Utilitarian Facebook Usage." Electronic Commerce Research and Applications 12 (4): 224-235.

Preece, J., B. Nonnecke, and D. Andrews. 2004. "The Top Five Reasons for Lurking: Improving Community Experiences for Everyone." Computers in Human Behavior 20 (2): 201-223.

Rafaeli, S., G. Ravid, and V. Soroka. 2004. De-lurking in Virtual Communities: A Social Communication Network Approach to Measuring the Effects of Social and Cultural Capital. In Proceedings of the $37^{\text {th }}$ Hawaii International Conference on System Sciences, Big Island. 
Reber R., and N. Schwarz. 2002. "The Hot Fringes of Consciousness: Perceptual Fluency and Affect." Consciousness and Emotion 2: 223-231.

Ringle, C. M., S. Wende, and S. Will. 2005. SmartPLS 2.0 (M3) Beta, Hamburg.

Roberts, J. A., I-H. Hann, and S. A. Slaughter. 2006. "Understanding the Motivations, Participation, and Performance of Open Source Software Developers: A Longitudinal Study of the Apache Projects.” Management Science 52 (7): 984- 999.

Schimmack, U. 2008. The Structure of Subjective Well-being. In The Science of Subjective WellBeing, 97-123, edited by M. Eid, and R. J. Larsen. New York: Guilford Press.

Schneider, A., G. Von Krogh, and P. JäGer. 2013. "What's Coming Next? Epistemic Curiosity and Lurking Behavior in Online Communities." Computers in Human Behavior 29 (1): 293303.

Singh, J. B., R. Chandwani, and M. Kumar. 2018. "Factors Affecting Web 2.0 Adoption: Exploring the Knowledge Sharing and Knowledge Seeking Aspects in Health Care Professionals." Journal of Knowledge Management 22 (1): 21-43.

Steenkamp, J. B. E., and H. Baumgartner. 1992. "The Role of Optimum Stimulation Level in Exploratory Consumer Behavior.” Journal of Consumer Research 19 (3): 434-448.

Sun, N., P. P. L. Rau, and L. Ma. 2014. "Understanding Lurkers in Online Communities: A Literature Review." Computers in Human Behavior 38: 110-117.

Tsai, H. T., and R. P. Bagozzi. 2014. "Contribution Behavior in Virtual Communities: Cognitive, Emotional and Social Influences.” MIS Quarterly 38 (1): 143-163.

Tsai, H. T., and P. Pai. 2013. "Explaining Members' Proactive Participation in Virtual Communities.” International Journal of Human-Computer Studies 71 (4): 475-491.

Valenzuela, S., N. Park, and K. F. Kee. 2009. "Is There Social Capital in a Social Network Site? Facebook Use, and College Students' Life Satisfaction, Trust, and Participation.” Journal of Computer-Mediated Communication 14 (4): 875-901.

Vogt, C. A., and D. R. Fesenmaier. 1998. "Expanding the Functional Information Search Model." Annals of Tourism Research 25 (3): 551-578.

Van Mierlo, T. 2014. “The 1\% Rule in Four Digital Health Social Networks: An Observational Study.” Journal of Medical Internet Research 16 (2): e33. 
Wairimu, J., and F. K. Andoh-Baidoo. 2018. "Factors that Influence Lurking Behaviors in Open Innovation Communities: The Role of Social Capital." In Proceedings of the 24th Americas Conference on Information Systems, paper 7, New Orleans.

Wasko, M. M., and S. Faraj. 2005. "Why should I Share? Examining Social Capital and Knowledge Contribution in Electronic Networks of Practice.” MIS Quarterly 29: 35-57.

Wenger, E. 1998. "Communities of Practice: Learning, Meaning and Identity." Cambridge: Cambridge University Press.

Wenger, E. 2011. “Communities of Practice A Brief Introduction.” Accessed Oct. 13, 2016. https://scholarsbank.uoregon.edu/xmlui/handle/1794/11736.

Wilensky, H. 1960. “Work, Careers, and Social Integration.” International Social Science Journal 12: 543-560.

Yang, X., G. Li, and S. S. Huang. 2017. "Perceived Online Community Support, Member Relations, and Commitment: Differences between Posters and Lurkers." Information \& Management 54 (2): 154-165. 